\section{Subacute Retrograde TAVI Migration Successfully Treated With a Valve-in-valve Procedure}

\section{Migración retrógrada subaguda de TAVI solucionada con un procedimiento valve-in-valve}

\section{To the Editor,}

A 65-year-old man with severe degenerative aortic stenosis (Figures $1 \mathrm{~A}$ and $2 \mathrm{~A}$ ) and preserved systolic function was evaluated by the Heart Team of our institution for surgical aortic valve replacement vs transcatheter aortic valve implantation (TAVI). A TAVI procedure was chosen because he had a heavily calcified aorta. He underwent a preprocedure computed tomography angiography to select the route, prosthesis type and prosthesis size for the procedure. He had no significant peripheral artery disease, and we therefore chose a transfemoral route. His aortic root area measured $430 \mathrm{~mm}^{2}$ on computed tomography angiography. The aortic root diameter measured on 2-dimensional transesophageal echocardiography was $24 \mathrm{~mm}$. We therefore chose an Edwards Sapien XT $26 \mathrm{~mm}$ valve. The TAVI procedure was undertaken (under transesophageal echocardiography) with balloon predilation, and no postdilation, without immediate complications. The balloon was prepared according to the manufacturer's recommendations (ie, no soft preparation, by using a lower amount of balloon saline, was undertaken). Fluoroscopy (Figure 1A and Figure 1B, and video 1 and video 2 of the supplementary material), and transesophageal and transthoracic echocardiography (Figure 2A and Figure 2B, and video 3 and video 4 of the supplementary material) confirmed appropriate prosthetic positioning with a mean gradient of $9 \mathrm{mmHg}$ and absence of relevant paravalvular leaks. However, 24 hours after the procedure, a follow-up transthoracic echocardiogram was performed and a de novo mean aortic gradient of $42 \mathrm{mmHg}$ was revealed (Figure 2C). The prosthetic valve had migrated retrogradely into the outflow tract, thereby uncovering the native valve, which was functioning again (Figure $1 \mathrm{C}$ and Figure 2D, video 5 and video 6 of the supplementary material). We reviewed the case and concluded that the prosthetic valve might have been positioned slightly too low and might have suboptimally expanded during the procedure. After discussion of the case in the Heart Team, a valve-in-valve procedure with a second $26-\mathrm{mm}$ Edwards Sapien XT valve was chosen (Figure 1D and video 7 of the supplementary material). This enabled successful treatment of the aortic stenosis and prevented further migration of the original prosthesis. The patient was discharged 3 days after the second procedure and at 1 year of follow-up he is free of heart failure and the prosthesis is working adequately. 

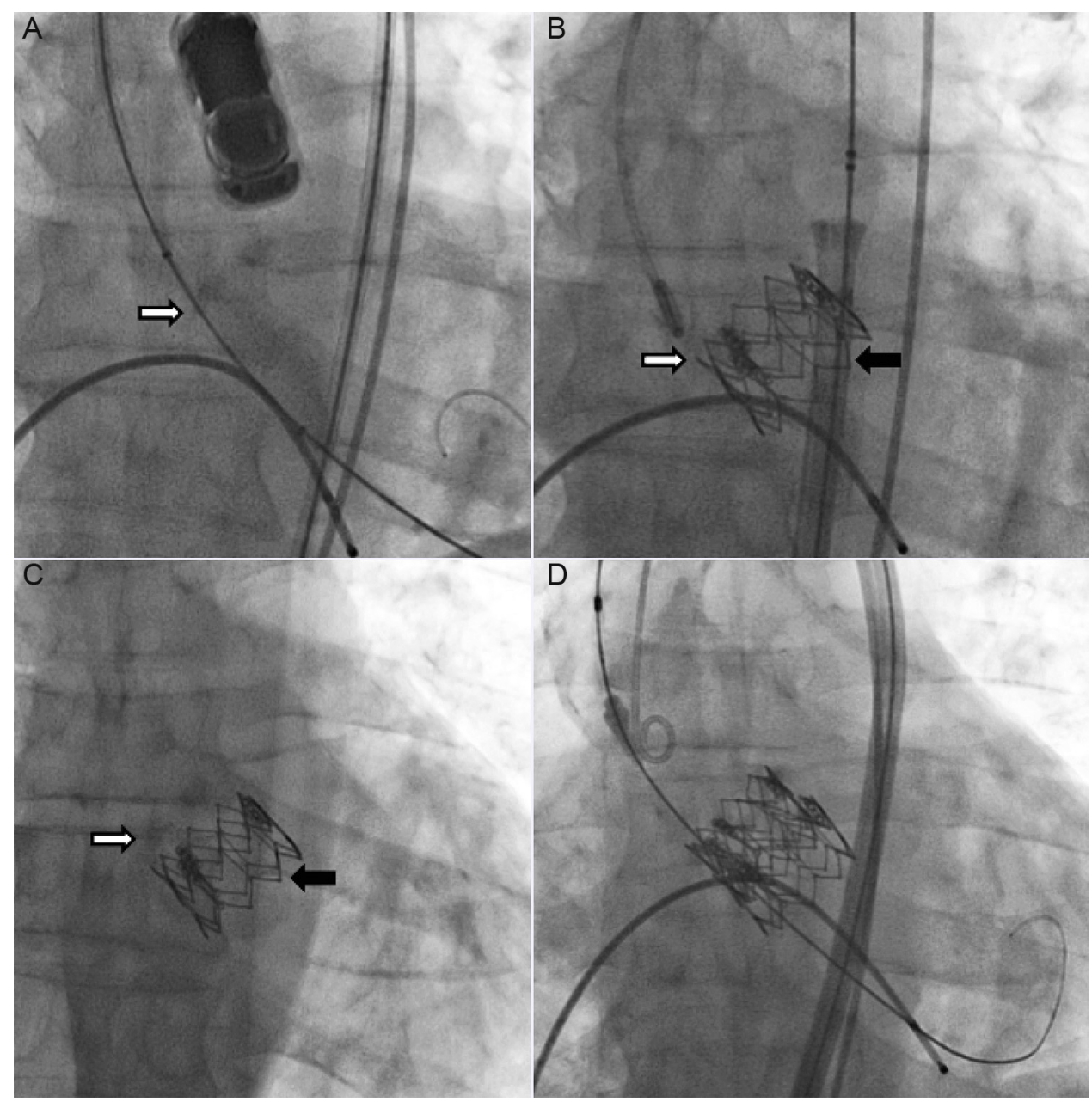

Figure 1. A, Fluoroscopy images depicting preimplantation. B, Immediate postimplantation. C, Prosthesis position following migration. D, Final result after the valve-in-valve procedure. White arrow pointing toward native valve. Black arrow pointing toward prosthesis.

Retrogade migration of the prosthetic valve following TAVI is rare. It can occur during the procedure, ${ }^{1}$ within the first few days after the procedure ${ }^{2}$ or subsequently. ${ }^{3,4}$ The first step in developing a solution is to identify the contributing factors for migration. These range from prosthesis malpositioning (ie, too low), ${ }^{1}$ suboptimal valve expansion, uneven or insufficient aortic annulus calcification leading to inadequate prosthesis fixation, aortic paravalvular regurgitation, valve undersizing, ${ }^{4}$ and anatomical or functional bicuspid valves. In our patient, the first cause was deemed responsible for this complication, although we cannot be sure that underexpansion did not also occur. It is as important to identify the true causes of migration as it is to exclude other factors. This enables appropriate solutions to be selected and also avoids potentially damaging ones. For example, wrongly considering valve undersizing as a cause of migration may lead to the subsequent use of an oversized valve with a high risk of further damage. Additionally, the use of fully repositionable valves may reduce the risk of malposition and migration. We also speculate that direct implantation (without predilation) could reduce the risk of this complication.
Once the causes of the migration have been determined, a surgical or percutaneous approach must be quickly chosen in a Heart Team setting, as the consequences of valve migration can be catastrophic if the valve extends beyond the outflow tract into the left ventricle cavity. In the few reports describing this complication, surgery was the preferred method in almost all published cases. Indeed, we found only 1 case in which this problem was solved by a percutaneous approach, ${ }^{5}$ but that was a case of valve undersizing and the complication still occurred during the procedure.

While surgery was considered in this case, we believed a valve-in-valve procedure was the safest way to solve the problem because the prosthesis was not interfering with the mitral apparatus, the patient had a porcelain aorta, and the migration was a consequence of valve subexpansion and slightly low positioning. The second prosthesis would be fixed not only in the native annulus but also on the original prosthesis, thereby preventing migration of both valves. This approach seems to have been justified by the patient's favorable outcome. 


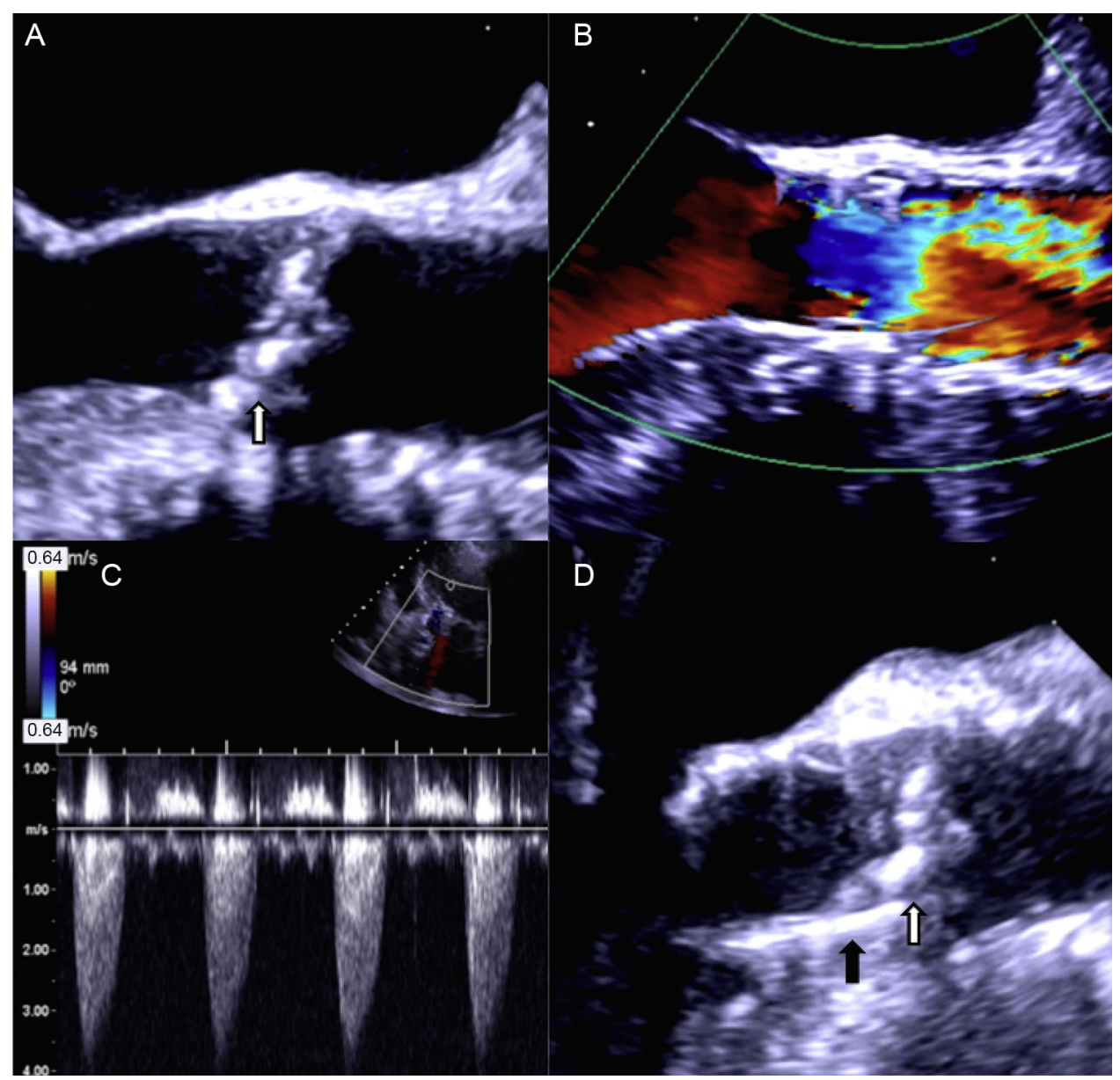

Figure 2. A, Echocardiographic images depicting preimplantation. B, Immediate postimplantation flow through prosthesis. C, Left ventricle-aorta gradient following prosthesis migration. D, Two-dimensional image of the prosthesis after migration. White arrow pointing toward native valve calcium. Black arrow pointing toward prosthesis.

\section{SUPPLEMENTARY MATERIAL}

Supplementary material associated with this article can be found in the online version available at doi:10.1016/j. rec.2016.08.003.

Miguel Nobre Menezes, ${ }^{\mathrm{a}, *}$ Pedro Canas da Silva, ${ }^{\mathrm{a}}$ Ângelo Nobre, Eduardo Infante de Oliveira, ${ }^{a}$ Pedro Carrilho Ferreira, ${ }^{a}$ and Fausto J. Pinto ${ }^{\mathrm{a}}$

${ }^{a}$ Cardiology Department, University Hospital Santa Maria/Centro Hospitalar de Lisboa Norte/CCUL, Lisbon, Portugal ${ }^{\mathrm{b}}$ Cardiothoracic Surgery Department, University Hospital Santa Maria/Centro Hospitalar de Lisboa Norte/CCUL, Lisbon, Portugal

* Corresponding author:

E-mail address: mnmenezes.gm@gmail.com (M. Nobre Menezes).

\section{REFERENCES}

1. Cao C, Ang SC, Vallely MP, Ng M, Adams M, Wilson M. Migration of the transcatheter valve into the left ventricle. Ann Cardiothorac Surg. 2012;1:243-244.

2. Clavel M-A, Dumont E, Pibarot P, Doyle D, De Larochellière R, Villeneuve J, et al. Severe valvular regurgitation and late prosthesis embolization after percutaneous aortic valve implantation. Ann Thorac Surg. 2009;87: 618-621.

3. Nkomo VT, Suri RM, Pislaru SV, Greason KL, Sinak LJ, Holmes DR, et al. Delayed transcatheter heart valve migration and failure. JACC Cardiovasc Imaging. 2014;7:960-962.

4. Prakash R, Crouch G, Joseph MX, Bennetts J, Selvanayagam JB, Sinhal A. Very late ventricular displacement of transcatheter aortic valve resulting in severe paravalvular regurgitation. JACC Cardiovasc Interv. 2014;7:e13-e15.

5. Showkathali R, Dworakowski R, MacCarthy P. Valve in valve implantation to prevent acute prosthetic valve migration in Transcatheter Aortic Valve Implantation (TAVI) Indian Heart J. 2015;67:598-599.

http://dx.doi.org/10.1016/j.rec.2016.08.003

1885-5857/

(c) 2016 Sociedad Española de Cardiología. Published by Elsevier España, S.L.U. All rights reserved.

\section{Transcatheter Aortic Valve Implantation in Patients With Arterial Peripheral Vascular Disease}

Implante percutáneo transfemoral de válvula aórtica en pacientes con enfermedad arterial periférica

\section{To the Editor,}

Transcatheter aortic valve implantation (TAVI) via the transfemoral route appears to improve survival and cause fewer complications than transapical implantation. Whenever possible, the transfemoral route should therefore be the first choice. ${ }^{1}$ 